\title{
BROUWER'S ANTICIPATION OF THE PRINCIPLE OF CHARITY*
}

\author{
by Göran Sundholm
}

\author{
Dedicated to J. J. de Iongh \\ on the occasion of his 70 th birthday.
}

My aim in the present paper is modest and mainly one of exposition: I want to re-examine some of Brouwer's views on the nature and function of language and present them in such a way that their close affinity with currently popular topics in the philosophy of language is brought out. Such a task seems worthwhile in that one not infrequently encounters the claim that Brouwer's position on meaning is out-and-out psychologistic in character. In view of my title it is no surprise that the topics from the philosophy of language are taken from within the theory of radical interpretation. The plan of my paper is as follows: in an introductory section some of the different formulations of the Principle of Charity that have been given in the literature are reviewed in order to continue with an exposition of Brouwer's general philosophy of intuitionism and, in particular, his philosophy of language as presented in three of his lectures ${ }^{1}$. The resulting picture of language is then compared with the theory of radical interpretation. In two digressions analogies with Carnap's Aufbau and (spät) Wittgensteinian rulefollowing are hinted at. Finally, I spell out some consequences that my reading of Brouwer's philosophy of language will have for the philosophy of (constructive) mathematics.

These matters of organization having been dealt with, it is a

* Meeting of the Aristotelian Society held at 5/7 Tavistock Place, London WCl, on Monday, 27 February, 1984 at 6.00 p.m. A postal delay made it impossible to print this paper in the Proceedings for $1983 / 4$.

'L. E. J. Brouwer 'Mathematik, Wissenschaft und Sprache', Monatshefte f. Math. u. Phys. 36 (1929), pp. 153-164.

'Willen, weten, spreken' in De uitdrukkingswijze der Wetenschap, kentheoretische voordrachten gehouden aan de Universiteit van Amsterdam (1932-1933), pp. 43-63. Also in Euclides (Groningen), Vol. 9 (1933), pp. 177-193.

'Consciousness, Philosophy and Mathematics', Proc. 10th intern. Congress of Philosophy, North-Holland. Amsterdam 1948, pp. 1235-1249. 
great pleasure to have the opportunity to conclude this opening paragraph by acknowledging many helpful conversations with Professor J. J. de Iongh on the foundations and philosophy of mathematics in general and how Brouwer could (or should!) be interpreted in particular. Although Professor de Iongh is likely to disagree with most of my conclusions, it is through these conversations that $\mathrm{I}$ have come to appreciate just how different Brouwer's position is from what popular expositions take it to be.

In an introductory section, I hope, one may be forgiven for once again covering very well-known ground. ${ }^{2}$ The Principle of Charity began life as part of 'an investigation into the nature of individuals', and it was, in fact, a very straightforward statement of a Description Theory of Proper Names ${ }^{3}$ :

And so we act on what might be called the Principle of Charity. We select as designatum that individual which will make the largest possible number of ... statements true.... We might say that the designatum is that individual which satisfies more of the asserted matrices containing the [name in question] than does any other individual. ${ }^{4}$

and

How does an individual manage to get itself hooked onto by an individual constant? The answer now lies before us. It does so by having those characteristics in virtue of which it satisfies more of the asserted matrices containing the constant in question than does any other individual. ${ }^{5}$

Many (and in my generation, I would say, most) students of Philosophical Logic and the philosophy of language would not

\footnotetext{
${ }^{2}$ Macdonald, G. and P. Pettit, Semantics and Social Science, Ch. 1, Routledge and Kegan Paul, London 1981, is a good source of background information.

${ }^{3}$ See S. Kripke, Naming and Necessity, Blackwell, Oxford 1980, pp. 64-70.

'N. L. Wilson, 'Substances Without Substrata', Review of Metaphysics 12 (1958-9), p. 532.

${ }^{5}$ Wilson, op. cit., p. 535.
} 
immediately associate the Principle of Charity with a Description Theory of Proper Names such as that given by Wilson in the above quotes. The principle which some of us got to know as that of Charity was introduced to us in such passages as:

The methodological advice to interpret in a way that optimizes agreement should not be conceived as resting on a charitable assumption about human intelligence that might turn out to be false. If we cannot find a way to interpret the utterances and other behaviour of a creature as revealing a set of beliefs largely consistent and true by our own standards, we have no reason to count that creature as rational, as having beliefs, or as saying anything. ${ }^{6}$

and

The general policy is . . to choose truth conditions that do as well as possible in making speakers hold sentences true when (according to the theory and the theory builder's view of the facts) those sentences are true. ${ }^{7}$

Here, in this version, the Principle of Charity is an a priori constraint on a project of radical interpretation: how should one best set about connecting the recursion clauses of a Tarskian truth-theory with how speakers actually use their language? The latter Principle of Charity gives an answer to this question. One should maximize agreement between truth (as seen by the interpreter) and what is held true by the speakers as shown by their (sincere) assertions. In a certain sense this Davidsonian version of the Principle of Charity may be viewed as a more or less natural extension of the original Wilsonian variant. There referents of proper names are fixed by means of weighted fit and, similarly, in the Davidson version, the (extension of a) Tarskian $\mathrm{T}$-predicate is determined by means of weighted fit. One can, as a matter of fact, find echoes of the Wilson Principle also in the writings of Davidson. Consider, e.g. the following well-known passage:

${ }^{6}$ D. Davidson, 'Radical Interpretation', Dialectica 27 (1973), p. 324.

'D. Davidson, 'Belief and the Basis of Meaning', Synthese 27 (1974), p. 320. 
how clear are we that the ancients-some ancients-believed that the earth was flat? This earth? Well, this earth of ours is part of the solar sytem, a system partly identified by the fact that it is a gaggle of large, cool, solid bodies circling around a very large, hot star. If someone believes none of this about the earth, is it certain that it is the earth that he is thinking about? ${ }^{8}$

Colin McGinn ${ }^{9}$ has critized Davidson's introduction of a referential scheme via the Principle of Charity on the basis of Kripke-style counter-arguments to the Description Theory of Proper Names ${ }^{10}$. He observes that such arguments show the autonomy of reference and (sentence-) truth in a theory of meaning. If we read off a scheme of reference from truth as determined according to Davidsonian Charity the result will be something like the Wilson variant and I agree with McGinn that this is unsatisfactory. What is unsatisfactory is that one of the two anchors of a Fregean theory of meaning ${ }^{11}$-the category of Proper Names-has its semantics completely reduced to that of the other, namely the category of Sentences. Thus the error seems to lie not so much in the use of Charity but in the suppression of reference as an independent notion. ${ }^{12}$

In fact, if we start our Charity considerations, not with the Wilson formulation, but with the Davidsonian variant, then the former is not the natural version of Charity for proper names. The following seems a better analogy with Charity: choose as referent of a name that individual to whom most speakers take it to refer. In this way the autonomy of reference is respected and the Principles of Charity for truth and reference are completely analogous. One should note that, just as there is a problem about identifying the 'sign of assent' in the case of Charity for sentences, there will be a corresponding problem of identifying

${ }^{8} \mathrm{D}$. Davidson, 'Thought and Talk' in S. Guttenplan (editor), Mind and Language, O.U.P. 1975, p. 21.

9'Charity, Interpretation, and Belief, Journal of Philosophy, LXXIV (1977), pp. 521-535.

${ }^{10} \mathrm{Kripke}$, op.cit.

${ }^{11}$ See Gareth Evans, The Varieties of Reference, Ch. 1, O.U.P. 1983, for a lucid exposition.

${ }^{12}$ Indeed, Davidson has carried this position to its logical conclusion in his 'Reality Without Reference', reprinted in Mark Platts (editor), Reference, Truth and Reality, Routledge and Kegan Paul, London 1980. 
the 'sign of reference' for the case of Charity for names. I will not, however, further investigate whether or not this formulation of Charity would stand up against the criticism of McGinn. Such an inquiry would take me far outside the scope of the present paper and, furthermore, there is growing agreement that Charity in the sense of Davidson is not what really matters in the construction of a theory of meaning:

The point of the notion of sense ... is thus tied to our interest in the understanding of behaviour, and ultimately our interest in the understanding-the fathoming-of people. We have not properly made sense of forms of words in a language if we have not, thereby, got some way towards making sense of its speakers. ${ }^{13}$

The Principle of Charity has been approached in this spirit by e.g. David Lewis ${ }^{14}$ :

it would be more charitable to make allowances for the likelihood that [the speaker's] circumstances-his life history of evidence and training, ...-may have led him understandably into error. We should at least forbear from ascribing to [him] those of our beliefs and desires which . . . he has been given no reason to share. We should even ascribe to him those errors which we think we would have made, or should have made, if our evidence and training had been like his.

McGinn explicitly refrains from arguing against the formulation of Lewis and he finds 'charity as to finding others consistent and rational highly compelling, ${ }^{15}$. The present version of Charity was dubbed the Principle of Humanity by Richard Grandy: ${ }^{16}$

we have, as a pragmatic constraint on translation, the condition that the imputed pattern of relations among beliefs, desires and the world be as similar to our own as possible

\footnotetext{
${ }^{13} \mathrm{John}$ McDowell, 'On the Sense and Reference of a Proper Name', reprinted in Platts (editor), op.cit., p. 142.

${ }^{14}$ 'Radical Interpretation', Synthese 27 (1974), p. 336.

${ }^{15}$ McGinn, op.cit., p. 535.

${ }^{16}$ 'Reference, Meaning, and Belief', Journal of Philosophy LXX (1973), p. 443.
} 
and it is this last formulation that I want to keep in mind in the next section where a review of Brouwer's lectures is given.

Brouwer's mature views about language are most forcefully presented in the three lectures mentioned above (see note 1), and, of these, the second-'Willen, weten, spreken'-which was delivered in Amsterdam 12 December 1932, is most relevant to my topic. It is a revised and extended Dutch version of the lecture which was given in Vienna on 10 March 1928 and which, it is said, brought Wittgenstein back into philosophical activity. In view of this latter circumstance one expects (or at least, I expected) that the Brouwer lectures would have been given careful attention and much commentary from, among others, Wittgenstein scholars. Somewhat surprisingly this is not the case, owing perhaps to linguistic difficulties ${ }^{17}$, and I have found only two discussions by British philosophers ${ }^{18}$. The three lectures, even though they are spread out over a period of twenty years, present (versions of) a fairly crystallized position which remains constant in spite of different manners of presentation on different occasions, and, in fact, essential features of the position can be traced to Brouwer's very first writings. ${ }^{19}$

Sometimes one encounters the view that mathematics (usually in the form of an axiomatic system) has to be justified in terms of a soundness proof for an appropriate formal semantics, or, perhaps, by means of a theory of meaning for the mathematical language in question. Brouwer is diametrically opposed to such a view; in his opinion mathematics is not responsible either to logic or to a theory of meaning. On the contrary, logic and language are not guarantees for, but parasites on, the essentially individualistic activity of doing mathematics, which does not stand in need of any justification whatsoever.

\footnotetext{
${ }^{17}$ The first, Vienna, lecture is in German. The second is in Dutch, while the third begins with a warning that Brouwer does not expect to be understood.

${ }^{18}$ G. T. Kneebone, Mathematical Logic, van Nostrand, 1963, pp. 319-321, and P. M. S. Hacker, Insight and Illusion, O.U.P. 1972, Ch. IV: 3.

${ }^{19}$ Cf. W. P. van Stigt, 'The Rejected Parts of Brouwer's Dissertation on the Foundations of Mathematics', Historia Mathematica 6 (1974), pp. 385-404. Here I also want to take the opportunity to express a general debt to van Stigt's unpublished doctoral dissertation Brouwer's Intuitionism, London 1971.
} 
Brouwer opens his lecture by singling out two levels of the autonomous activity of mathematics, namely mathematical attention and mathematical abstraction. Both are basic forms of action of the individual's will to live. There are two stages of mathematical attention: temporal attention and causal attention. The former, temporal attention, or, perception of the move of time, 'may be described as the falling apart of a lifemoment into two different things, one of which gives way to the other, but is retained by memory ${ }^{\prime 20}$. Through this relegation of one thing to memory it is separated from the I and becomes part of 'the world of sensation experienced by mind"21. This temporal duality, or pair of temporal appearances, in its turn, may be viewed as a member of a new duality and thus the three-member sequence of temporal appearances arises. In this way, Brouwer says, through 'selfdeployment' ( $=$ iteration?) of the intellectual Urphenomenon, one will get the sequence of temporal appearances of arbitrary multiplicity. Here I will depart from Brouwer's order of exposition in order to be able to register one of my difficulties with his view. He proceeds by illustrating the causal attention before explaining mathematical abstraction, and I want to reverse the order of his account. ${ }^{22}$ The temporal attention does not suffice to give mathematics. For this we need the mathematical Urintuition which results from divesting the temporal dualities of all objectual content so that only the pure form, 'the common substratum', of all pairs remains. Through selfdeployment of the Urintuition all of mathematics, and in particular the natural numbers, are generated. My difficulty is that, while I can understand (?) how one reaches each individual number through successive repetitions of the Urintuition, I do not see how one

\footnotetext{
${ }^{20}$ This is a part of the 'First Act of Intuitionism', Brouwer's Cambridge Lectures on Intuitionism (D. van Dalen, editor), C.U.P. 1981, p. 4. Brouwer remained faithful to this characterization of the Urphenomenon throughout his career. Already among the rejected parts of the dissertation from 1907 we find
}

The primordial phenomenon is simply the intuition of time in which repetition of "thing in time and again thing" is possible [van Stigt, op.cit., p. 394]

and similar passages can be found in many of Brouwer's writings from the intervening years.

${ }^{21}$ German: Anschauungswelt. Dutch: Aanschouwingswereld. The translation I use is the one preferred by Brouwer in analogous passages from the 1948 lecture.

${ }^{22}$ 'Account' in the sense of description and not in the sense of justification. Brouwer does not give an account in the latter sense. He tells us what he does and how. I just don't understand him at this point. 
gets the notion 'pure form of (temporal) sequence of arbitrary multiplicity'. That is, I do not see how one proceeds from the individual numbers, or pure forms, $0,1,2,3, \ldots$ to the grasp of Number, without the use of something more. In fact, if selfdeployment means iteration (and if it does not, I don't even see how to reach the individual numbers), then the notion of Number is already built into the selfdeployment. (Cf. Wittgenstein, 'A number is an exponent of an operation.', Tractatus 6.021. $)^{23}$

Mathematical abstraction does not just give us the Urintuition of mathematics. It can also interact with causal attention in order to formulate scientific laws. The causal attention consists in the (mental) 'identification' of different sequences of appearances, and the result is called a causal sequence. A particular instance of causal attention is given by the condensation of individual 'things', that is, Brouwer says, causal sequences that are 'simple or complex units which persist in the world of sensation experienced by mind'. They are 'permutable' in time and completely separated from the subject. It should be stressed that for Brouwer, both temporal and causal attention are 'free-willphenomena', which, so to speak, can be switched on and off at will. In the exercise of his will to live the individual subject uses causal attention for cunning acts ${ }^{24}$, and hereby causal connections in the world are brought about by the subject. (Brouwer emphasizes that there are no causal connections in the world, except for those which are thus created by the subject.) Through the cunning act, a desired member of a causal sequence (the aim) is realized indirectly by the bringing about of another member of the sequence (which need not be desirable on its own) (the means). An example would be filling a glass of water as a means towards realizing the aim of quenching thirst. Through cunning acts the subject creates, and maintains, a causal sphere of influence. This causal sphere influences, and is self influenced by, the conative activity of the subject, in that threatening appearances are eliminated, while useful ones are added to it. Mathematical

\footnotetext{
${ }^{23}$ W. W. Tait, 'Finitism', Journal of Philosophy LXXVIII (1981), pp. 539-540, and 'Against Intuitionism', Journal of Philosophical Logic (12), pp. 173-182 treats of this and related problems.

${ }^{24}$ This concept can be traced back already to Leven, Kunst en Mystiek from 1905.
} 
abstraction now interacts with causal attention in that several causal sequences are subsumed under a common form or law. Here, according to Brouwer, lies the starting point of exact science.

A Viennese digression. The history of ideas is full of striking coincidences of simultaneous discoveries of similar results by one or more researchers. The discovery of the planet Neptune is perhaps the most spectacular instance. The different, but equivalent, formulations of Quantum Mechanics by Heisenberg and Schrödinger give another well-known example. The Foundations of Mathematics provide many instances around 1930: Tarski and Herbrand proved the Deduction Theorem, Gentzen and Jaskowski discovered Natural Deduction, Church and Turing proved the Undecidability theorem etc.. It is a striking coincidence that, at the very time when Brouwer delivered his 'Mathematik, Wissenschaft und Sprache' in Vienna, Carnap must have been busy preparing his Logische Aufbau der Welt for the press. (The preface is dated May 1928.) Carnap's infinitely more detailed account has many similarities with Brouwer's position. Brouwer constructs his world through, or perhaps better, tells us that his world is given through, among other things, persisting causal sequences. Carnap uses, as the basic elements of his construction system, what he calls 'elementary experiences'. (This is a primitive concept, but might perhaps be understood as a section of the stream of consciousness.) The central relation between these is that of a 'likeness recollection' and from this a world is built. Objects become regularities in the stream of elementary experiences (which strongly reminds one of Brouwer's 'identifications'). The name of Carnap's position-methodological solipsism-describes Brouwer's view in a most appropriate way. The crucial difference between the two is that Carnap is a 'constructionist' or translator. He wants to show that on the basis of his primitives he can, using the logic of Principia, give definitions of the concepts one needs in order to talk about the world. Brouwer, on the other hand, does nothing of the sort. He tells us what his world is like, and not what you would have to do to translate your world into his.

Brouwer and his lecture do not get mentioned in the Aufbau, 
but we know from Carnap's 'Intellectual Autobiography' ${ }^{25}$ that he heard Brouwer. There can be no question of any direct influence, however. The first draft of the Aufbau was written in the years 1922-1925, well before Brouwer's visit to Vienna, but it remains an interesting task to work out the comparison between the two in some detail.

Any higher degree of complexity in the use of mathematical attention and, in particular, mathematical abstraction, presupposes that the subject has progressed beyond the most primitive stages of cultural organization and development. It is only at the more advanced levels that the third basic manifestation of the individual's will to live comes into action, namely the imposition of will by means of sound. This is the origin and sole function of language; it is sometimes in the individual's selfinterest to subordinate his will to that of another being in order that, say, their causal spheres of influence should work in unison. To this end, in order to direct the work of other wills, there arises the need for the transmission of will between subjects. All other uses and functions of language are parasitic on this public role. There is, however, no certain guarantee that the transmission of will takes place as desired. This, then, is the reason why language is an imperfect vehicle for mathematical activity; one can never be sure that the mathematical acts that have been carried out by one subject can be transmitted to another through language. Mathematics remains an essentially languageless activity. The subject has to carry out his mathematical acts, perform his constructions through more or less complex iterations of the Urintuition, and there is no way to ensure that another subject can copy, or even imitate, the constructions in question. (Causal sequences are individuated in subjects so copying seems out of the question.) That communication succeeds, at least partially, is due to the empirical circumstance that in an organized social community there is sufficent uniformity in the structure of the desire-patterns of the different individual wills. Through drill in language-use, through social and moral conventions, religious beliefs, and so on, a sufficient parallelism is ensured for the operation of the wills of different

\footnotetext{
${ }^{25}$ The Philosophy of Rudolf Carnap, (P. A. Schilpp, editor), Open Court, La Salle, 1963, p. 49 .
} 
individuals to make communication at least partially possible. This thesis of the parallelism of wills bears a strong resemblance to Grandy's Humanity constraint, but Brouwer uses his thesis the other way round. In the theory of radical interpretation it is taken as known that we do understand each other, ${ }^{26}$ and then, in order to account for how this is at all possible, a homologous structure of propositional attitudes to that of our own is postulated in the subjects of interpretation. Brouwer, on the other hand, notes that, as a matter of empirical fact, such homology exists, at least to some degree, and that, hence, at least partial communication is sometimes possible.

His anticipation of topics from the theory of radical interpretation goes further than this though. In his discussion of the use of causal attention in conjunction with mathematical abstraction, he observes, apropos the idea of a scientific theory of one's fellow beings, that

It is an essential hypothesis for mathematical contemplation of one's fellow men to assume that in each there is present a mathematico-scientific mechanism of attention, action and reflection. ${ }^{27}$

and also that

It is an essential presupposition for understanding between human beings that in each the structure of rational contemplation is the same. ${ }^{28}$

In conclusion let us note that Brouwer is very sceptical of, and sometimes even hostile to, language ${ }^{29}$. It therefore seems appropriate to take note of the fact that he is a great master of its use. His Dutch, in particular, has very distinctive features, and it is almost impossible to improve on, or to paraphrase, his various formulations.

\footnotetext{
26"We do understand each other! That's a datum" as Michael Dummett put it in a panel-discussion in Nijmegen, October 1983.

${ }^{27}$ Brouwer, op.cit. 1932, p. 6.

${ }^{28}$ loc.cit., p. 8. My translation in both cases.

${ }^{29}$ Hacking, Why Does Language Matter To Philosophy?, C.U.P., p. 149, comments on the value judgements that are built into the names of the Principles of Charity and Humanity. Is it, in fact, charitable to assume that someone speaks the truth when he asserts what we assert? And do only they count as human who believe and feel as we do? These questions are very much in the spirit of Brouwer.
} 
Another Viennese digression. The subject matter of mathematics is given by the Urintuition and is private to the subject. Language, on the other hand, is through and through social. Hence, mathematics is, and remains, an essentially languageless activity. This could perhaps be called a 'private language argument'. Indeed, if we recollect a more famous private language argument, it is instructive to realize that the objects of mathematics would have to be given in a private language such as is ruled out by Wittgenstein. Another point of connection lies in Brouwer's insistence on the free-will character of the mathematical acts; we are free to carry out our constructions as we please. If in a causal sequence I should choose to iterate, say, $2000,2002,2004,2008$ instead of $2000,2002,2004,2006$, who could find me wrong? To everyone his own mathematical activity, and if, by transmitting beautiful constructions to other subjects, he can give someone pleasure through the beauty of the construction, so much the better. I have here cast a Wittgensteinian example in a Brouwerian setting. It seems a worthwhile task to make a detailed study of the Remarks on the Foundations of Mathematics and compare it with Brouwer's Vienna lecture. It is also interesting to note that when David Bloor ${ }^{30}$ attempts to carry out a 'strong programme for the sociology of knowledge' for mathematics and logic on the basis of Wittgenstein's work, the position he reaches shows strong similarities with a position that can be extrapolated from Brouwer's view, namely the position which results from a reversal of Brouwer's chain of thought: start with his view on language and apply this to mathematical discourse in order to read off a philosophy of mathematics. Indeed, first Wittgenstein builds on Brouwer and then Bloor is able to discover a Brouwerian position in Wittgenstein.

In this section I want to indicate briefly what consequences a literal reading of Brouwer will have for the philosophy of mathematics. If we take his word for what he takes himself to be doing, it appears that the current practice for investigations of

\footnotetext{
${ }^{30}$ David Bloor, 'Wittgenstein and Mannheim on the Sociology of Mathematics', Stud. Hist. Phil. Sci. 4 (1973), pp. 173-91.
} 
intuitionistic mathematics is all wrong, or at least at strong variance with what the Founder of Intuitionism thought and how he worked. Nowadays, constructive mathematics in general, and intuitionism in particular, are often presented as axiomatic extensions of Heyting's basic axiom system for firstorder intuitionistic logic, very much in the style of classical firstorder theories with the primitive vocabularies and non-logical axioms. Such a separation of logic and mathematics is not to the taste of Brouwer; logic is in no way prior to mathematics. On the contrary, a 'logical law' is valid because for each 'instance' of the law one can in fact carry out the construction as required. It is not that the mathematical action can be performed because the law is valid; the explanatory effect goes in the other direction according to Brouwer.

Michael Dummett, in his review of Brouwer's Collected $W_{o r k s}{ }^{31}$, gives an elegant and lucid presentation of meaningtheoretical issues that he finds at the root of intuitionism. He ascribes three principles to Brouwer, namely

(i) mathematical statements have content

(ii) this content is given in terms of what counts as a proof of it

(iii) the meaning of any statement must be determined by its composition.

These principles, however, do not square with Brouwer's own account of his mathematical activity. There is, according to him, no such thing as the content of a mathematical statement. The notion of meaning is hopelessly imprecise and one cannot base mathematical activity thereon. To talk about definite contents and determination of meaning for mathematical statements makes no sense for Brouwer: his mathematics is an essentially languageless activity. On the other hand, Dummett's principles give a quite precise description of Constructive mathematics as based on Heyting's semantical explanations of logical and mathematical concepts. Elsewhere ${ }^{32}$, I have dealt with Heyting's formulations in some detail and tried to show how they should

\footnotetext{
${ }^{31}$ Mind LXXXIX (1980), pp. 605-615.

${ }^{32}$ 'Constructions, Proofs and the Meaning of the Logical Constants', Journal of Philosophical Logic 12 (1983), pp. 151-172.
} 
be read. I argue there that one must differentiate between Heyting the Brouwerian intuitionist and Heyting the semanticist of constructivism. Dummett is impressed by the circumstance that 'within the framework provided by the fundamental principles (i)-(iii), Brouwer was as permissive as possible'. I do not think that Brouwer worked within the framework (i)-(iii), but Heyting the semanticist did, and it is certainly true that Brouwer was permissive. Heyting does not give his 'proofexplanations' for typically intuitionist conceptions, such as quantification over choice sequences. If the standard explanations were applicable there also, one ought to be able to decide the status of Brouwer's Bar Theorem at once, but it is, and remains, a controversial principle.

The moral I want to draw is this: Heyting and Brouwer were not engaged in the same enterprise, and, therefore, one should be wary of applying the semantical schemes of Heyting to the writings of Brouwer. Nevertheless, an interesting technical question suggests itself as a suitable conclusion of my paper. Heyting explained propositions as intentions towards constructions (which when carried out produce construction-objects of certain types) and showed how the logical constants correspond with certain operations on construction-objects, e.g. pair-formation for conjunction and function-abstraction for implication and universal quantification. Is it possible to find a 'non-standard' model of this notion of proposition (with its ensuing theory of constructions) for which Brouwer's practice, e.g. in the form of the Bar Theorem, is validated? 


\section{THE ARISTOTELIAN SOCIETY}

\section{Officers 1984/85}

President: Professor P. Alexander

Honorary Secretary and Editor: R. M. Sainsbury

Treasurer: Professor G. N. Walton

Monographs Editor: A. B. Savile

Assistant Treasurer: Gail Grayson

Executive Committee: The President, the Secretary, the Treasurer, the Monographs Editor, Professor Manser, Professor Burnyeat, Dr. Davies, Mr. Woods

Monographs Committee: the Monographs Editor, Dr. Davies, Dr. Hornsby

\section{Members}

[Please inform the Assistant Treasurer, Aristotelian Society, King's College, London WC2R 2LS, of any errors or omissions.]

ACKRILL, Professor J. L., Brasenose College, Oxford. [1948]

ACLAND, Miss T. L., King's College Hall, Champion Hill, London, SE5 8AN. [1984]

ACTON, Mrs B., 5 Abbotford Park, Edinburgh 10. [?]

AKESSON, Professor Elof, Skolradsvagen, 9, S-223, 67 Lund, Sweden [1935]

ALEXANDER, Professor P., 36 Woodstock Road, Redland, Bristol, BS6 7EP. [1945]

ALLEN, Mr C., 5e Castlebar Park, Ealing, London, W5 IDD. [1984]

ALLEN, C.B., King's College, Philosophy Dept. [1984]

ALLEN, H. J., Dept of Philosophy, Adelphi University, Carden City L.I., New York 11530, U.S.A. [1966]

ALTHAM, Mr J. E. J., Gonville \& Caius College, Cambridge, CB2 1TA [1972]

AMINI-ALIABADY, Mr M., 56 Shelgate Road, London, SW11 1BG. [1982]

ANDREW, Mr David, 29 Barrett Road, London E17 9ES. [1980]

ANGLUIN, Dr D. J. C., 202 Ferme Park Road, London N8 9BN [1983]

ANNAS, J., St Hugh's College, Oxford. [1971]

ANSCOMBE, Professor G. E., 3 R ichmond Road, Cambridge. [1956] APPIAH, Dr A., 3388 Yale Station, New Haven, CT 06520, U.S.A. [1983]

ARCOLEO Mr S., Via Galilei 33, 28100 Novara, Italy. [1969] 